\title{
Transformation of electrical energy into hydrogen and its storage
}

\author{
Manfred Wanner ${ }^{\mathrm{a}}(\mathrm{D}$ \\ Max-Planck-Institut für Plasmaphysik, Boltzmannstr. 2, 85748 Garching, Germany
}

Received: 24 February 2021 / Accepted: 18 May 2021

(C) The Author(s) 2021

\begin{abstract}
The German national hydrogen strategy strongly supports the development of technologies to produce, store and distribute green hydrogen in large quantities to reduce greenhouse gas emissions. In the public debate, it is often argued that the economic success of green hydrogen depends primarily on improved efficiencies, and reduced plant costs over large volumes and higher capacities. However, an economy based on the large-scale use of green hydrogen must also take into account the thermodynamic and technical limitations of the processes and components. This study therefore aims to assess the main technical challenges of the German approach to the large-scale use green hydrogen as a future energy carrier.
\end{abstract}

\section{Introduction}

In June 2020, the German federal government adopted a national hydrogen strategy to support the energy turnaround through increased use of hydrogen [1]. So far, hydrogen has been produced almost exclusively from natural gas, crude oil or coal, thereby releasing large amounts of the greenhouse gas $\mathrm{CO}_{2}$. Instead, "green" hydrogen is suggested to be used in future as dominant energy carrier. Green hydrogen is produced exclusively from renewable electricity by electrolysis of water, with only oxygen as a by-product. Germany plans a budget of 9 billion Euros for developing efficient and exportable technologies, promoting the production and use of hydrogen from renewable sources, and building the necessary infrastructure for supraregional storage and distribution [1].

Similar technology targets, although less ambitious, were already pursued between 1992 and 1997 in the frame of the European Quebec Hydro-Hydrogen Pilot Project (EQHHPP). This project aimed at converting $100 \mathrm{MW}$ of Canadian hydropower by electrolysis into hydrogen, ship it as cryogenic liquid by special barges or in chemical form to Europe and develop the necessary logistics to distribute it to passenger cars, buses, and airplanes to reduce $\mathrm{CO}_{2}$ emissions [2].

This study aims to analyze the consequences of a comprehensive green hydrogen economy considering the present state of technology. In Germany, approximately 20 billion standard cubic meters $\left(\mathrm{Nm}^{3}\right)$, corresponding to 1.8 million tons of pure hydrogen, is produced annually for the chemical industry [3]. If this amount of hydrogen were produced by electrolysis, the

\footnotetext{
a e-mail: manfred.wanner@ipp.mpg.de (corresponding author)
} 
German $\mathrm{CO}_{2}$ emissions would reduce by 20 megatons [4]. However, the annual electricity production of all German wind power plants would have to be used for this purpose. If hydrogen is to be used in the future not only as chemical raw material but also as an energy carrier, the required quantities will increase significantly.

The permanent fluctuations of wind and solar energy are a growing problem in the expansion of renewable energies. In order to keep the grid voltage and frequency constant during reduced wind and solar supply, conventional power plants with a short start-up time or fast reacting energy storage systems with sufficiently high capacity must be switched on to match the demand. On the other hand, a surplus of renewable energy can presently be countered only to a limited extent by exporting electric power or by switching off wind power plants. The interventions to stabilize the grid are becoming more and more frequent as the share of wind and solar energy increases. However, even with the strongest expansion of renewable energies, hourly or daily wind and solar energy shortfalls cannot be ruled out. For this reason, large energy storage facilities and replacement power plants will become increasingly necessary to achieve a short-term balance between electricity demand and supply [5].

Due to their size and cost and their ecological footprint in production, stationary lithiumion batteries will not be usable for energy quantities in the GWh range. The capacity of environmentally friendly pumped storage power plants is also exhausted after only a few hours. Due to the geographical conditions in Germany a further expansion of pumped storage power plants with significantly larger storage volumes is not foreseeable. Combined heat and power plants, which also have a short ramp-up time, consume mainly natural gas or diesel oil and therefore emit climate-damaging carbon dioxide. Moreover, as they will be used less and less with the further expansion of renewable power generation; their operation is becoming increasingly uneconomic. Following the national hydrogen strategy, excess electricity from renewable sources should be stored in the future in the form of green hydrogen in gaseous or liquid form. If required, this hydrogen can be converted back into electricity in fuel cells and thus contribute to a balance between the fluctuating supply and the respective demand. As national resources of renewable energy may be limited, the German strategy also considers an import of energy in the form of hydrogen.

All process steps for the generation of hydrogen from electricity, its compression, liquefaction and storage and its conversion back into electricity are well understood, and industrial plants of different capacities are available on the market. The chemical industry has been safely processing large quantities of conventionally produced hydrogen for decades. As this hydrogen is just produced according to demand, its storage and its conversion into electricity are not an issue.

The production of green hydrogen is significantly more expensive than hydrogen from fossil fuels. In the public debate, it is often argued that the economic success of green hydrogen mainly depends on improved efficiencies, and reduced plant costs over large numbers and higher capacities. However, an economy based on large-scale use of green hydrogen has also consider the thermodynamic and technical limits of the processes and components. This study aims therefore to assess the main technical challenges of the German approach to use green hydrogen extensively as future energy carrier by two examples: The first example estimates the impact of generating an energy reserve of one Gigawatt electrical power for a period of $24 \mathrm{~h}$ from hydrogen previously produced by electrolysis from renewable electric power. The second example analyses the consequences of a study made by Fraunhofer ISI on a future supply of green hydrogen for fuel cell powered heavy trucks in Germany by a distributed system of hydrogen service stations.

To understand the technical limits, chapter 2 starts with the thermodynamic boundary conditions of the conversion of renewable electric energy into hydrogen, its storage and its 
conversion back into electricity. Chapter 3 estimates the capacity of the components required to provide a full day energy reserve of one Gigawatt based on green hydrogen, while chapter 4 focuses on the hydrogen filling stations for heavy fuel cell-powered trucks. Chapter 5 draws some conclusions from the results of the analysis.

\section{Thermodynamic boundary conditions}

Although the principle of electrolysis is widely used, intensive research has been going on for many years to develop the technology toward more efficient electrolyzers with higher capacities and lower degradation. Under ideal, i.e., loss-free thermodynamic conditions, only $3.00 \mathrm{kWh}$ of electric energy (= lower heating value) would be required to dissociate the water molecules and produce one standard cubic meter $\left(\mathrm{Nm}^{3}\right)$ corresponding to $0.09 \mathrm{~kg}$ of hydrogen at atmospheric pressure. In addition, about $0.54 \mathrm{kWh} / \mathrm{Nm}^{3}$ of heat has to be provided to vaporize the water, resulting in a total energy demand of $3.54 \mathrm{kWh} / \mathrm{Nm}^{3}$ (upper heating value). The decomposition of water also produces $0.5 \mathrm{Nm}^{3}$ of oxygen per $\mathrm{Nm}^{3}$ of hydrogen. This oxygen is usually not used any further, as it can be produced more economically by other processes.

In accordance with the requirements for the subsequent process steps, modern electrolyzers do not produce hydrogen at atmospheric pressure, but rather at pressures of 20 to 80 bar. The incompressible water can be pumped to higher pressures with little energy. However, due to their larger specific volume, the gases produced have to work against the existing pressure. This increases the minimum energy for electrolysis by the isothermal compression energy for the two product gases. At a pressure of $20 \mathrm{bar}$, this amounts to $0.14 \mathrm{kWh}$, at $80 \mathrm{bar}$ correspondingly to $0.20 \mathrm{kWh}$.

The hydrogen produced in the electrolyzer is saturated with water vapor and must therefore be dried. If the hydrogen shall be liquefied also other impurities need to be reduced to less than $10 / 1,000,000$ (= $10 \mathrm{ppm})$ to avoid clogging by frozen gases. The minimum energy requirement for drying can be estimated at approximately $0.03 \mathrm{kWh} / \mathrm{Nm}^{3}$.

Realized electrolyzers typically consume $4.0-5.5 \mathrm{kWh}$ of electricity per $\mathrm{Nm}^{3}$ of hydrogen produced. Without consideration of the required heat, these values correspond to efficiencies of 55-75\% in relation to the lower heating value of hydrogen. The optimum efficiencies apply only at low current densities. With increasing current density, hydrogen production increases, however, at the expense of decreasing plant efficiency [6]. The largest plant currently under construction in Wesseling (Germany) shall consume $10 \mathrm{MW}$ to produce 1300 tons of hydrogen per year with an output pressure of 20 bar [7]. The specific energy consumption of $5.37 \mathrm{kWh} / \mathrm{Nm}^{3}$ [8] corresponds to $56 \%$ efficiency compared to the lower heating value. In Hamburg, another ambitious project with an electrical power input of $100 \mathrm{MW}$ is planned [9].

At comparatively low pressures, limited quantities of hydrogen can be added to the existing natural gas network for heating purposes. Large quantities of pure hydrogen, however, have to be compressed to a much higher pressure or liquefied to reduce their volume. The ideal (isothermal) compression of one $\mathrm{Nm}^{3}$ of hydrogen from 1 to 150 bar requires a minimum energy input of $0.16 \mathrm{kWh}$. Depending on the capacity and pressure ratio, isothermal efficiencies of designed hydrogen compressors range between about $60 \%$ and $70 \%$. Therefore, compression requires at least 1.4 times the minimum energy. Almost all of the compression energy needs to be discharged to the cooling water and is finally dumped to the environment.

Reciprocating compressors are state of the art for medium and larger hydrogen throughputs. As the adiabatic compression results in higher gas temperatures, up to six compression 
stages with intercoolers are needed to reach pressures of several hundred bars. These compressors suffer from their maintenance effort and their large moving masses, limiting their use typically at about $100,000 \mathrm{Nm}^{3} / \mathrm{h}$. For much higher gas throughput, turbo-compressors are common in process plants. For hydrogen, however, turbo-compressors cannot be employed economically, as they suffer from a very low stage compression ratio due to speed limitations of the impeller wheels.

High-pressure storage of hydrogen in steel tanks achieves densities of only $35 \mathrm{~kg} / \mathrm{m}^{3}$ even at pressures of 600 bar. Due to the required large wall thicknesses and the associated high container weight in relation to the stored gas volume, this method is only used for small and medium volumes (gas cylinders, high pressure trailers).

Caverns in salt domes are being discussed as gas storage for large quantities of hydrogen. Such cavities are sufficiently tight, so that gas losses are acceptable. For the noble gas helium, such a storage facility was realized several years ago in Gronau-Epe in northern Germany [10]. Helium is stored there in a $275,000 \mathrm{~m}^{3}$ brine cavern located at a depth of $1400 \mathrm{~m}$. The storage facility is operated at a pressure of around 170 bar by displacing the brine, resulting in a maximum filling of 47 million $\mathrm{Nm}^{3}$. The storage is emptied by pumping back the brine at almost constant pressure. After emptying, the gas has again to be cleaned from brine water and other impurities, for which additional energy is required. Depending on the further use, a large part of the energy required during the initial compression to 170 bar may be lost again during the emptying, cleaning and expansion to low pressures. As the lighter hydrogen molecule may escape somewhat faster by diffusion than helium, more effort is needed to select a cavern and maintain the tightness of the containment by proper operation [11].

Liquid organic hydrogen carriers (LOHC) such as dibenzyltoluol (DBT) are considered promising candidates for safe storage and transport of hydrogen at higher densities but at ambient pressure [12]. At elevated temperatures and pressures and in contact with a catalyst, hydrogen can be reversibly absorbed and released in a chemical process. During the exothermic process of hydrogenation, densities of up to $57 \mathrm{~kg} / \mathrm{m}^{3}$ (approximately $80 \%$ of the liquid hydrogen density) can be reached without mechanical compression [13]. While considerable heat is released during hydrogenation, discharge of the hydrogen is endothermic, requiring $0.81 \mathrm{kWh} / \mathrm{Nm}^{3}$ of heat at temperatures between 250 and $320^{\circ} \mathrm{C}$. This high demand of energy is similar to the demand during liquefaction and makes this type of storage interesting only for small and medium flow rates or if excessive waste heat is available. For vehicles, the exchange of discharged against charged LOHC fluid is being considered to shorten the fueling process. The high density of the stored hydrogen represents nevertheless only about $6 \%$ of the LOHC density requiring to move large carrier masses charged with relatively small amounts of hydrogen. Modified liquid petrol gas tankers are considered for the long distance transport of hydrogen charged LOHC. With a typical tanker volume of $250,000 \mathrm{~m}^{3}$, only 15 tons of hydrogen, equivalent to $0.5 \mathrm{GWh}$ of electric energy, can be delivered during one trip, while about 250,000 t of the liquid carrier is permanently moved as ballast. To discharge the hydrogen within $24 \mathrm{~h}$, a flow of LOHC need to be withdrawn from the vessel, heated and dehydrogenated for some time by adding $5 \mathrm{MW}$ at about $300{ }^{\circ} \mathrm{C}$, recooled to ambient temperature and pumped-back into the vessel as ballast and absorber for the next filling. After the discharge, and depending on the further use, the hydrogen may require compression and additional cleaning from impurities.

Compared to high-pressure and chemical storage, hydrogen liquefaction achieves a much higher density of $71 \mathrm{~kg} / \mathrm{m}^{3}$ and can store twice as much hydrogen in a given volume compared to compression to 600 bar. The ideal thermodynamic process for liquefying hydrogen at $-253{ }^{\circ} \mathrm{C}$ requires only $0.36 \mathrm{kWh} / \mathrm{Nm}^{3}$. The currently largest modern hydrogen liquefiers have a capacity of around 30 tons per day (corresponding to $14,000 \mathrm{Nm}^{3} / \mathrm{h}$ ) and require about 
$0.90 \mathrm{kWh} / \mathrm{Nm}^{3}$. In a European study [14], promising plant concepts with capacities of up to 150 tons per day were investigated, in which an energy input of less than $0.60 \mathrm{kWh} / \mathrm{Nm}^{3}$ should be achievable.

The cryogenic liquid hydrogen has to be stored in double-walled, thermally insulated containers to keep the losses by evaporation low. The world's largest liquid hydrogen tank is currently being built at the Kennedy Space Center for the American space program [15]. With an outer diameter of $25 \mathrm{~m}$ and a usable volume of $5,300 \mathrm{~m}^{3}$, this tank can store approximately 4.1 million $\mathrm{Nm}^{3}$ of hydrogen. For many applications, the cryogenic liquid must first be warmed up to room temperature, requiring $0.11 \mathrm{kWh} / \mathrm{Nm}^{3}$ of heat. In order not to stress the overall energy balance additionally, it would be useful to couple the warm-up to another process requiring refrigeration. Since the liquid is stored slightly above atmospheric pressure, one could even consider a process where the heat is used also to compress the hydrogen.

Across the country, hydrogen can be distributed by liquid trailers, compressed hydrogen trailers, or pipelines. While a liquid hydrogen trailer can transport approx. $3500 \mathrm{~kg}$ corresponding to $40,000 \mathrm{Nm}^{3}$, the capacity of a high pressure trailer with a delivery pressure of $500 \mathrm{bar}$ is limited to a maximum of $1100 \mathrm{~kg}$ or $13,000 \mathrm{Nm}^{3}$. For overseas transport, tankers are planned similar to those used to transport liquid natural gas. In Japan, a liquid hydrogen tanker with a capacity of almost 90 tons of liquid hydrogen, corresponding to 1 million $\mathrm{Nm}^{3}$, is currently under construction [16].

Pipelines for hydrogen gas are in operation distributing comparatively small quantities for petrochemical applications, e.g., in central Germany, with a total length of approx. $380 \mathrm{~km}$ [17]. However, the maximum nominal diameters of $300 \mathrm{~mm}$ and pressures of less than $50 \mathrm{bar}$ are far from sufficient for the future distribution of very large quantities of hydrogen. In order to avoid frequent compressor stations along the pipeline to compensate for the pressure losses, pipe diameters of at least $600 \mathrm{~mm}$ are required for the expected hydrogen flow rates and operating pressures of around 100 bar. The existing natural gas network has corresponding diameters and design pressures over long distances. However, this network cannot be used for pure hydrogen due to the diffusion and embrittlement tendency of the pipe material and the higher hazard potential [18]. The design and construction of a pure hydrogen network and the approval of the route over long distances is therefore much more complex than for conventional natural gas pipelines. At high pressure, the long pipelines store enormous amounts of hydrogen. However, similar to the electric network, gas supply and demand need to be matched to keep the pressure in the pipeline within agreed limits. Different to caverns, pipelines can therefore not "breath" a lot to quickly absorb and release large quantities of gas from fluctuating sources.

Handling, distribution and storage of the hydrogen require additional effort to compensate for losses, pressure drop, and minimize the heat input to the cryogenic fluid. In present applications, these losses vary significantly [19] and depend strongly on the technical and financial effort for their reduction. For this study, we can assume a conservative loss of 5\% of the energy content of the hydrogen.

At the end of the process chain, part or all of the gaseous hydrogen shall be re-converted to electrical energy in fuel cells. There the hydrogen combines with oxygen from the air to form water while generating electricity and heat. This process works in principle in reverse direction to an electrolyzer, releasing $3.54 \mathrm{kWh} / \mathrm{Nm}^{3}$ of work and heat. Ideally, a share of $3.00 \mathrm{kWh}$ per $\mathrm{Nm}^{3}$ of hydrogen could be harvested as electrical energy. Because of losses in the fuel cell the electric yield is less, while the heat to be removed increases. The largest proton exchange membrane fuel cell stacks installed by 2020 have an electrical output power of $1 \mathrm{MW}$ and aim at a hydrogen consumption of $700 \mathrm{Nm}^{3}$ at the beginning of operation [20]. Long-term durability of fuel cells is still a subject of research and development as the stacks 
Table 1 Thermodynamic minimum and real energies for $1 \mathrm{Nm}^{3}$ of hydrogen

\begin{tabular}{lll}
\hline & Ideal energy $\left(\mathrm{kWh} / \mathrm{Nm}^{3}\right)$ & Real energy $\left(\mathrm{kWh} / \mathrm{Nm}^{3}\right)$ \\
\hline Electrolyzer (20 bar, purification) & 3.17 & $4.0-5.5$ \\
Compression (150 bar)/liquefaction & $0.16 / 0.36$ & $0.23 / 0.90$ \\
Handling/distribution/storage & 0.00 & 0.15 \\
Fuel cell output & 3.00 & 1.33 \\
Input energy/output energy & $1.1-1.2$ & $3.3-4.9$ \\
\hline
\end{tabular}

suffer from degradation by cyclic loads and poisoning of the membranes [21]. To account for the fluctuating operation and an some degradation, an average consumption of $750 \mathrm{Nm}^{3} / \mathrm{h}$ hydrogen per $1 \mathrm{MW}$ of output power is assumed. This corresponds to an efficiency of $44 \%$ related to the ideal work. Under these conditions, $1.66 \mathrm{MW}$ of heat has to be removed by appropriate cooling unless it can be combined with other processes. The individual fuel cell initially supplies a direct current with a low voltage of $1.2 \mathrm{~V}$. By coupling many cells followed by inverters this low voltage must then be transformed to the high $\mathrm{AC}$ voltage required for transmission.

A comparison of the ideal and real thermodynamic processes from the electrolyzer, through high-pressure or liquid storage of the hydrogen to the retransformation into electricity for an energy equivalent of one $\mathrm{Nm}^{3}$ of hydrogen is shown in Table 1 .

The table shows that under loss-free conditions, only $1.1 \mathrm{kWh}$ (high-pressure storage) to $1.2 \mathrm{kWh}$ (liquid storage) of input electricity would be required to recapture $1 \mathrm{kWh}$ at the output of the fuel cell. Due to the different losses, the actual electrical input increases to about $4.0 \mathrm{kWh}$ per recovered $\mathrm{kWh}$. This breakdown considers only the primary electric energy from the grid. Additional effort for the water supply for the electrolyzer, heating, and cooling, capital investment, operation and maintenance, gas distribution, and infrastructure downgrades the economic viability of the energy transformation further. As hydrogen liquefiers and compressors work already quite efficient, efficiency improvements of some percent for the electrolyzers and fuel cells will therefore not improve the overall situation fundamentally.

Liquid gas storage is restricted by the economic operation of the liquefier and the installation of large, ground based liquid storage tanks. As the liquid pipelines need to be extremely well insulated, distribution of the cryogenic liquid to consumers is limited to short distances of a few kilometers or, in the case of road tankers, to moderate quantities.

\section{Providing an energy reserve using green hydrogen}

The following example considers the production and storage of green hydrogen to establish an energy reserve for bridging a temporary lull in renewable electricity. Since the capacity of large pumped storage power plants is exhausted after only a few hours, a conversion chain is considered where green hydrogen shall provide an electrical output of $1 \mathrm{GW}$ for a period of $24 \mathrm{~h}$. This corresponds roughly to the capacity of one large power plant or $9 \%$ of the average capacity of all wind power plants currently installed on land in Germany. Compared to the current gross annual electric power consumption in Germany of $540 \mathrm{TWh}$, this reserve would only cover about $1.6 \%$ of the average daily consumption [22]. 
The assessment starts at the end of the transformation chain, i.e., at the fuel cells. To generate $1 \mathrm{GW}$ of power during $24 \mathrm{~h}$, about 1000 units of the largest fuel cells currently available must operate in parallel. These units must be supplied with $750,000 \mathrm{Nm}^{3} / \mathrm{h}$ or a total of 1620 tons of hydrogen during $24 \mathrm{~h}$. With an efficiency of $44 \%$, around $1.66 \mathrm{GW}$ of heat and $608 \mathrm{~m}^{3} / \mathrm{h}$ of condensed water have to be removed during electricity production. In view of the huge quantities of gas, the fuel cells should be arranged in close proximity to the hydrogen storages, to avoid a complex pipeline network and keep transport losses small. Delivery by trailer or tanker is practically impossible, as this would require unloading and simultaneous processing of around 1500 high-pressure gas trailers or 460 liquid trailers during 24-h of operation.

Liquefying this hydrogen reserve would take about 54 days, if we assume that in the medium term, only hydrogen liquefiers with a capacity of 30 tons per day are available. During this time, the liquefier will consume about $16 \mathrm{GWh}$ of renewable power, which again is dissipated as heat to the cooling water. Even with the studied future 150 tons per day liquefiers, a complete filling of the storage tanks would still take 11 days. However, since the liquid storage is only occasionally charged and emptied, operating a large liquefier for only a few days seems completely uneconomic. Smaller plants, which can be operated for slightly longer periods, may therefore be more advantageous, despite their poorer efficiency.

A liquid storage tank for 1620 tons of hydrogen must have at least $22,500 \mathrm{~m}^{3}$. This volume corresponds to about four tanks of the size of the world's largest tank presently under construction. Emptying the liquid storage tanks within $24 \mathrm{~h}$ should be unproblematic, as shown by the standard charging of the US space launchers shortly before take-off.

Underground storage at an assumed working pressure of 150 bar requires a cavern with a net working volume of at least $145,000 \mathrm{~m}^{3}$, about half of the volume of the brine cavern realized for helium. However, the cavern must be emptied within $24 \mathrm{~h}$ during operation. Whether a brine cavern can be emptied out of geological reasons so quickly is questionable.

Charging of this underground storage could be managed even within one day by about eight large reciprocating compressors. Assuming an input pressure of 20 bar and $70 \%$ isothermal compressor efficiency, only about $1.7 \mathrm{GWh}$ of electrical energy is required, which again is released to the cooling water. The use of several compressors provides redundancy and allows coping with a fluctuating hydrogen supply.

If it can be accepted that loading of the liquid or high-pressure storage takes several days or weeks, the situation for the production of hydrogen is relaxed. Assuming that $100 \mathrm{MW}$ electrolyzers are available with an overall power consumption of $5 \mathrm{kWh} / \mathrm{Nm}^{3}$, one unit could produce the required gas reserve within 38 days. Of the $90 \mathrm{GWh}$ of electrical energy consumed during production, $36 \mathrm{GWh}$ is again released as heat. In addition to the electric power, fresh water has to be provided at a moderate rate of $16 \mathrm{~m}^{3} / \mathrm{h}$. Though the electrolyzer capacity can be split to draw their energy almost anywhere from the grid, it would again make sense to install them close to the storage location in order to minimize the distribution losses.

A schematic process chain indicating the flow of electrical energy, heat, water, and hydrogen by different colors is shown in Fig. 1. Considering the specific figures derived in chapter 2, electrolysis, compression for underground storage or liquefaction consumes about 92 to $106 \mathrm{GWh}$ renewable energy to provide a one-day "emergency power supply" of $24 \mathrm{GWh}$.

The difference to the thermodynamic ideal process for this temporary storage of $24 \mathrm{GWh}$ is about 70 to $80 \mathrm{GWh}$ of heat at moderate temperatures, which is dumped to the environment, unless it can be combined with other processes.

Creating the energy reserve as liquid from fluctuating renewable sources is ruled out by the capacities and economic operation of the liquefiers. The huge liquid hydrogen storage vessels, which need to be installed on-ground near the liquefier, require active cryogenic cooling and 


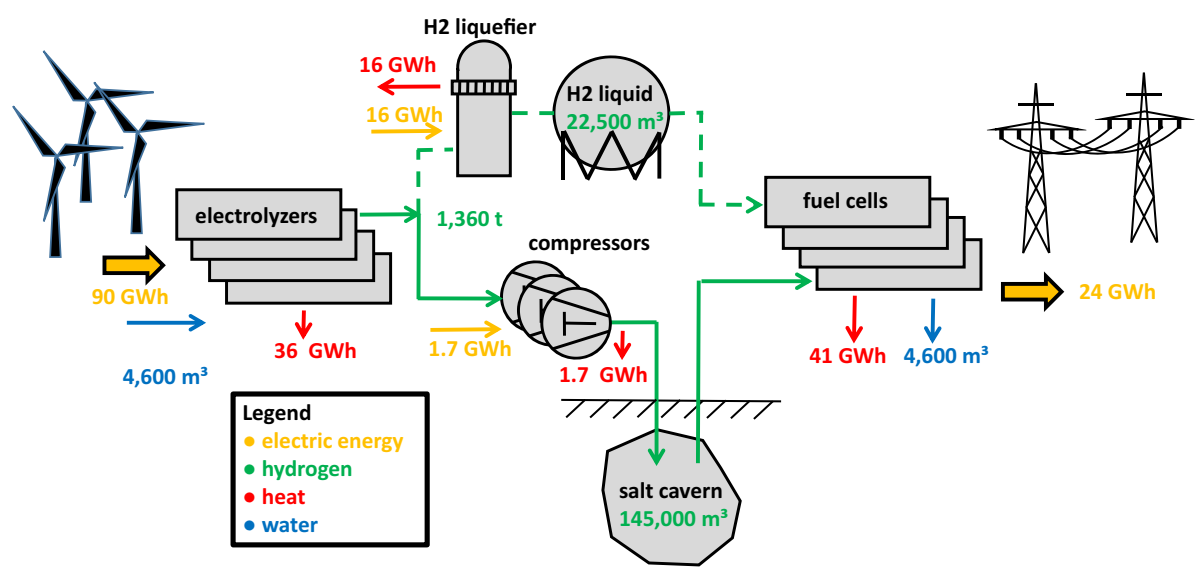

Fig. 1 Schematic process chain, indicating the flow of electrical energy, hydrogen, heat, and water for liquid or high-pressure underground storage

are a further bottleneck for the liquid train. In addition, the import and distribution of large quantities of liquid helium by tankers from abroad are limited by the capacities of liquid trailers and the complex design of long cryogenic pipelines.

Underground gas storage has an advantage that fluctuating capacities can be realized to a limited extent by connecting several electrolyzers and compressors in parallel. The state of the art of reciprocating compressors allows processing large and variable hydrogen flow rates without problems. A cavern of the size as realized for helium in Gronau-Epe could absorb hydrogen with an energy equivalent of about $100 \mathrm{GWh}$. However, many more caverns of this type, mainly located in the northern part of Germany, will be required to balance between the fluctuating supply of renewable electricity and the demand.

The analysis reveals the technical limits of a short-term storage of a comparable small fraction of renewable electricity in the form of hydrogen. If instead, $1 \mathrm{GW}$ of excess electric power shall be temporarily absorbed from the grid, to produce hydrogen at a conversion rate of $5 \mathrm{kWh} / \mathrm{Nm}^{3}$, a hydrogen flow of about $200,000 \mathrm{Nm}^{3} / \mathrm{h}$, i.e., $18 \mathrm{t} / \mathrm{h}$, would need to be processed and stored. Such large hydrogen rates would require $162 \mathrm{~m}^{3} / \mathrm{h}$ of clean water, sufficient to supply about 30.000 people in Germany. Such quantities may raise environmental problems in arid areas with excess solar or wind power. In such cases, seawater could be desalinated using some of the primary energy, reducing the overall efficiency further.

\section{Hydrogen filling stations for heavy fuel cell-powered trucks}

In line with the EU Green Deal, the transport and mobility sector shall reach carbon neutrality by 2050 . Therefore, fuel cell-powered trucks are prominent elements in the German national hydrogen strategy. Heavy trucks are particular suited for fuel cell drives as they travel long distances every day along the main highways. This allows economic operation and fueling of the trucks and simplifies the installation of the fueling infrastructure.

According to a working paper of Fraunhofer ISI [23], about 1.3 million tons of hydrogen would be required annually by 2050 to supply all heavy fuel cell trucks through a network of about 140 service stations distributed along or near the German highways. This amount is of the order of the total quantity of hydrogen, which is currently produced in Germany by conventional steam reformers. In order to ensure daily trips of the trucks with a single fueling 


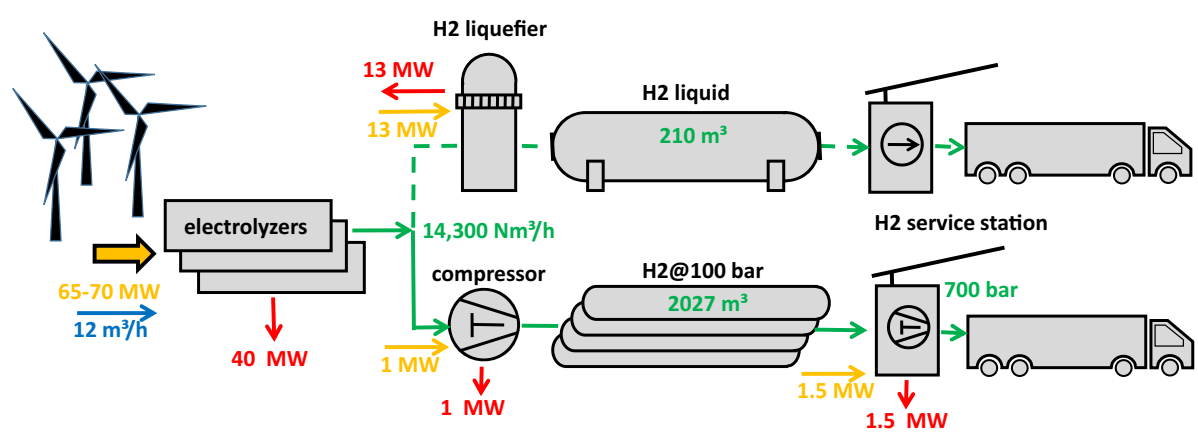

Fig. 2 Process chain of a single hydrogen service station. Regarding the legend of the colors, refer to Fig. 1

stop, while keeping the tank volume reasonable, the hydrogen fuel need to be delivered as liquid or at a pressure of 700 bar.

Although filling stations with different capacities shall be available in future, we will assume that in the average, each of these service stations shall deliver the same quantity, i.e., about 31 tons per day during 300 days per year.

To produce this quantity of hydrogen each of these gas stations would need an arrangement of about 20 electrolyzers with a total capacity of about $14,300 \mathrm{Nm}^{3} / \mathrm{h}$ consuming permanently about $65-70 \mathrm{MW}$ of electricity and $12 \mathrm{~m}^{3} / \mathrm{h}$ of treated water! Along with the hydrogen production, some $40 \mathrm{MW}$ of heat is again rejected.

Liquefaction of this quantity would require the installation of one of the presently largest hydrogen liquefiers near each gas station consuming about $13 \mathrm{MW}$. For economic operation, the liquefier needs to be fed with a continuous flow of hydrogen day and night. As fueling of the trucks may happen primarily during half of a day, a liquid storage vessel with a volume of at least $210 \mathrm{~m}^{3}$ holding 15 tons needs to be considered to balance between supply and demand.

Alternatively, compression of the electrolyzer output first to 100 bar and finally to $700 \mathrm{bar}$ could be achieved by an arrangement of medium-sized piston compressors consuming in total only about 2.5 MW. Buffering a half day's production at 100 bar would require a volume of $2027 \mathrm{~m}^{3}$ equal to about 100 high pressure cylinders with a diameter of $1 \mathrm{~m}$ and a length of $25 \mathrm{~m}$ !

A summary of the results of this assessment is illustrated in Fig. 2. As the service station shall provide the fuel continuously, the figures indicate powers, and flow rates contrast to energy and mass as used in Fig. 1.

The import of part of the hydrogen quantity by liquid or high-pressure gas trailers appears again unrealistic considering their limited capacities. Alternatively, gaseous hydrogen could be delivered from central production facilities through dedicated high-pressure pipelines. Depending on the fueling capacity of the service station, pipelines with diameters of $200 \mathrm{~mm}$ to $300 \mathrm{~mm}$ at a pressure of 100 bar would be sufficient to reach any central production site in Germany.

In summary, each of the 140 truck service stations would comprise a large and complex arrangement of plants, operated by a team of experienced engineers and operators. Each facility would comprise high-voltage transmission in the range of 70-80 MW, large lowvoltage transformers, water processing facilities, electrolyzers, compressors, and/or one or more liquefiers, large buffer volumes, cooling towers and filling terminals to feed several trucks in parallel. Operation of so many subsystems resembles more a chemical plant rather than a conventional gas station. Finally, the operation has to manage continuous fluctuations of the resources and the variable demand by the trucks. 


\section{Conclusions}

All technologies for producing green hydrogen by electrolysis, compression, liquefaction, and storage as liquid or at high pressure and its reconversion to electricity exist on the market at power levels up some megawatts. Scaling these technologies to the hydrogen quantities and production rates required for only one gigawatt during one day shows already significant technical limits. As hydrogen liquefiers and compressors work already quite efficiently, efficiency improvements of some percent for electrolyzers and fuel cells will not improve the overall economy of the energy transformation significantly.

Liquid hydrogen production is limited at maximum capacities of about 150 tons per day for single plants, which is equivalent to an energy content of only $5 \mathrm{GWh}$. Efficient operation of such large plants requires continuous supply of renewable electric power. However, already well below this liquefaction limit, the storage of such hydrogen quantities on ground in huge cryogenic vessels and their distribution by long insulated pipelines or an armada of liquid trailers appear unrealistic. The high energy density makes liquid hydrogen an attractive fuel for mobile applications, which run on a regular basis, like buses, trucks, taxis or ferries. While the liquefaction efficiency improves with the increasing capacity, distribution of some 30 to 150 tons of liquid per day to local stations remains a challenge.

High-pressure gas storage in caverns offers fundamental advantages over liquid storage for very large quantities. They can be filled in accordance with the fluctuating supply by a number of reciprocating compressors and discharged through a network of pipelines. However, it remains to be investigated whether a sufficient number of caverns suitable for hydrogen can be identified in Germany and close to the electrolyzers or fuel cells.

The supply of clean water may not affect the operation of electrolyzers in Germany. In arid areas, with a high potential of wind and solar energy and no access to the sea, clean water may become, however, another bottleneck for the operation of the electrolyzers.

The example of a future infrastructure to supply all heavy fuel cell trucks in Germany by green hydrogen also demonstrates that each of the service stations needs to be accompanied by a complex system of plants, which need to be supplied by a constant rate of renewable electric power. The electric power demand of about $10 \mathrm{GW}$ for all service stations would already consume the electricity produced by all presently installed German wind turbines.

Importing large quantities of hydrogen by road is limited by the maximum size of liquid or high-pressure trailers or the size and length of the pipelines. Pipelines with sufficient diameter are in principle able to deliver the required quantities. As natural gas pipelines cannot be simply used for pure hydrogen, a network of new pipes and recompression stations from remote locations with excess of wind or solar power need to be installed. Large liquid hydrogen ships may reduce the transport problem between different continents. Upon arrival in Germany, the distribution of large amounts of liquid by trailers across the country represents, however, a severe bottleneck. Feeding the hydrogen into a future pipeline network would simplify distribution, however at the expense of additional energy to vaporize and compress the gas, which has been liquefied before with great effort.

In summary, the balancing of fluctuations of renewable energy though green hydrogen seems feasible only up to a level of several GWh per day. However, the German government's idea of replacing a significant share of conventionally produced electric energy in the order of TWh with hydrogen does not stand up to scientific analysis.

Funding Open Access funding enabled and organized by Projekt DEAL. 
Open Access This article is licensed under a Creative Commons Attribution 4.0 International License, which permits use, sharing, adaptation, distribution and reproduction in any medium or format, as long as you give appropriate credit to the original author(s) and the source, provide a link to the Creative Commons licence, and indicate if changes were made. The images or other third party material in this article are included in the article's Creative Commons licence, unless indicated otherwise in a credit line to the material. If material is not included in the article's Creative Commons licence and your intended use is not permitted by statutory regulation or exceeds the permitted use, you will need to obtain permission directly from the copyright holder. To view a copy of this licence, visit http://creativecommons.org/licenses/by/4.0/.

\section{References}

1. The national hydrogen strategy https://www.bmbf.de/files/die-nationale-wasserstoffstrategie.pdf. Accessed June 2020

2. G. Giacomazzi, J. Gretz, Euro-Quebec Hydro-Hydrogen Project (EQHHPP): A challenge to cryogenic technology, in Proceedings of the Low Temperature Engineering and Cryogenics Conference, Southampton, UK, (1992), p. 767

3. Wasserstoff: Produktion nach Prozess 2020 I Statista. https://de.statista.com

4. Potentialatlas für Wasserstoff, ENCON.Europe GmbH (2018). https://www.innovationsforumenergiewende.de/fileadmin/user_upload/Potentialstudie-fuer-gruenen-Wasserstoff-in-Raffinerien.pdf

5. F. Wagner, Surplus from and storage of electricity generated by intermittent sources. Eur. Phys. J. Plus 131, 445 (2016). https://doi.org/10.1140/epjp/i2016-16445-3

6. P. Lettenmeier, Efficiency - Electrolysis, White paper. Siemens Corporate Technology, Strategy \& Business Development, Germany, Article No. SICM-T10001-00-7400

7. H2R Wasserstoff Rheinland, https://www.wasserstoff-rheinland.de/project/shell-elektrolyse/. Accessed June 2020

8. HGasXMW.pdf, https://www.itm-power.com/hgas10mw. Accessed Nov 2020

9. Hamburg to build world's largest hydrogen electrolysis plant (2019). https://www.hannovermesse.de/en/ news/news-articles/hamburg-to-build-worlds-largest-hydrogen-electrolysis-plant

10. P. Dörne, Untergrundspeicherung, Jahresbericht 2016 der Bergbehörden Nordrhein-Westfalens, Ministerium f. Wirtschaft, Innovation, Digitalisierung und Energie des Landes NRW, (2016), p. 32

11. A. Ozarslan, Large-scale hydrogen energy storage in salt caverns. Int. J. Hydrog. Energy 37, 14265 (2012)

12. M. Niermann et al., Liquid organic hydrogen carrier ( $\mathrm{LOHC}$ - assessment based on chemical and economic properties. Int. J. Hydrog. Energy 44, 6631 (2019)

13. https://www.crt.tf.fau.de/forschung/arbeitsgruppen/komplexe-katalysatorsysteme-und-kontinuierlicheverfahren/wasserstoff-und-energie/. Accessed Oct 2020

14. D.O. Berstad, J.H. Stang, P. Nekså, Large-scale hydrogen liquefier utilizing mixed-refrigerant pre-cooling. Int. J. Hydrog. Energy 35(10), 4512-4523 (2010)

15. NASA to build world's largest $\mathrm{H} 2$ tank https:/www.gasworld.com/nasa-to-build-worlds-largest-h2-tank/ 2016328.article. Accessed May 2019

16. Kawasaki, Worlds first liquefied hydrogen carrier, https://global.kawasaki.com/en/corp/newsroom/news/ detail/?f=20191211_3487. Accessed Dec 2019

17. Repurposing gas infrastructure for hydrogen | 2020 | Siemens Energy Global (siemensenergy.com). https://www.siemens-energy.com/global/en/news/magazine/2020/repurposing-natural-gasinfrastructure-for-hydrogen.html

18. Z. Hafsi, M. Mishra, S. Elaoud, Hydrogen embrittlement of steel pipelines during transients. Procedia Struct. Integr. 13, 210 (2018)

19. M. Genovese et al., Hydrogen losses in fuelling station operation. J. Clean. Prod. 248, 119266 (2020)

20. Ballard, ClearGen ${ }^{\mathrm{TM}}$ multi MW systems, Technical data sheet. https://pdf.directindustry.com/pdf/ballard/ cleargen-multi-mw-systems/22779-383697.html

21. M.M. Mench, E.C. Kumbur, T.N. Veziroglu, Polymer Electrolyte Membrane Fuel Cell Degradation (Elsevier, Amsterdam , 2012). (ISBN 978-0-12-386936-4)

22. A. Breitkopf, Bruttostromverbrauch in Deutschland bis 2020, Statistica Portal, https://de.statistica.com. Accessed Nov 2020

23. Ph. Rose, M. Wietschel, T. Guann, Working paper Sustainability and Innovation, Fraunhofer ISI, Nr. S09 (2020) 